\title{
Microwave assisted extraction of organic compounds
}

\author{
M. Letellier and H. Budzinski*
}

LPTC, UPRESA 5472 CNRS, Université Bordeaux I, 351 cours de la libération, 33405 Talence, France

\begin{abstract}
Microwave energy has been developed recently for the extraction of organic compounds from environmental matrices after its use in inorganic chemistry for trace metal analysis. The development in microwave techniques has occurred because of a need for a rapid, safe and cheap method. Conventional techniques for the extraction of solid matrices (such as Soxhlet) are time and solvent consuming and the analysis of numerous samples in environmental studies is limited by the extraction step. This review recalls the importance of the extraction step in the analytical procedure for the analysis of organic contaminants and the principles of extraction of solid matrices (sediment, soil, air particulate matter...). The theory of microwave heating is summarised and the microwave ovens used in analytical chemistry are described. Then, the review attempts to summarise all the studies about microwave assisted extraction for organic contaminants, on one hand in multimode microwave ovens in closed vessels and on the other hand in focused microwave ovens at atmospheric pressure. The microwave assisted extraction methods of volatile compounds are summarised. Finally, advantages of methods compared to conventional extraction are discussed.
\end{abstract}

Key words. Microwave - extraction - organic contaminants.

\section{Introduction}

Progress of analytical systems allows nowadays the detection of very low quantities of individual contaminants. Qualitative and quantitative analysis concludes a long procedure of sample treatment. The extraction is the least evolved step of analytical procedure since one of the most used techniques (Soxhlet extraction) has been developed by F. Soxhlet in 1879 [1]. The Soxhlet method proceeds by iterative percolation of the sample with recondensed vapours of solvent. This method is one of the most used technique for extraction of organic contaminants. It is used for the certification of matrices by organisms such as NIST (National Institute of Standards and Technology, Gaithersburg, MD, USA) [2,3] or BCR (Community Bureau of Reference of European Commission, Brussels, Belgium) and is recommended in the methods of the US Environment Protection Agency.

With the problem of solvent consumption, often in large quantities and toxic, and the problem of time consumption, supercritical fluid extraction has been developed since the 80 $\mathrm{s}$ to avoid the use of organic solvents and to increase the speed of extraction [4-6]. However this method is limited by its cost and by its selectivity which requires advanced optimisation.

With the expansion of domestic ovens, the heating mode with microwave energy has become familiar. Although microwave energy has high potential, microwave ovens have only recently appeared in chemical laboratories. The main reasons are that the heating mechanism is very different from the well established mode (conduction and convection), and that chemical reaction processes under microwaves are not well understood [7]. However the use of microwaves has created increasing interest for the last few years.

Use of microwave domestic ovens in the laboratory has been mentioned for the first time by Samra et al. in 1975 for the treatment of biological samples for metal trace analysis [8]. Since this date, the technique of digestion has been developed $[9,10]$. The first publications in organic synthesis have appeared in $1986[11,12]$. These studies have shown different kinetics compared to conventional heating and higher synthesis recoveries [13]. The extraction of organic compounds by microwave irradiation has appeared with the work of Ganzler et al. [14] and Lane and Jenkins [15] in 1986. Since this date, numerous laboratories have studied the analytical possibilities of this new extraction technique.

Microwave heating has been applied to the extraction of organic contaminants such as polycyclic aromatic hydrocarbons, polychlorobiphenyls, pesticides, herbicides, phenols, neutral and basic priority pollutants in various matrices such as sediments, soils or atmospheric particles... The main purposes are the reduction of extraction time and the reduction of solvent quantity. The decrease of solvent waste, of solvent release into the environment and of human exposure is also important. The extraction technique must be efficient and not selective. If the first studies have used domestic ovens, laboratory ovens, dedicated to organic analysis are now available and can differ by the microwave technology and the pressure conditions.

This review recalls the importance of the extraction step in the analytical procedure for organic contaminants, and the principles of the extraction of solid matrices (sediments,

* Correspondence and reprints.

Received October 20, 1998; revised December 09, 1999; accepted January 19, 1999. 
soils, air particulate matter...). The theory of microwave heating is summarised and the microwave ovens used in analytical chemistry are described. Then, the review attempts to summarise all the studies about microwave assisted extraction of non and semi-volatile organic contaminants, on one hand in multimode microwave oven in closed vessels and on the other hand in focused microwave ovens at atmospheric pressure. The influence of parameters such as time, temperature, power, nature of solvent, nature of matrix, moisture content and the stability of compounds are discussed. The microwave assisted extraction methods of volatile compounds are summarised. Finally, advantages of these methods compared to conventional extraction are reviewed.

\section{Importance of the extraction step in the analytical procedure}

Natural samples can rarely be used in their raw state. Their nature must be compatible with the detection method. The analysis of organic contaminants requires pre-treatment of the sample. Different steps of sampling, extraction and purification are necessary before the determination and the quantification of individual compounds.

The principal step of the sample treatment is the extraction of analytes from matrix, which consists of transfer of the compounds into a solvent. Extraction is rarely selective. The raw extract is then constituted of studied compounds at trace level but also of co-extracted compounds (endogenous compounds, macromolecules, other contaminants...) which can interfere during the analysis. It is necessary to purify extracts, to reconcentrate or to dilute. Analysis of studied compounds is more and more advanced. Each compound or isomer is identified and quantified. The analysis is performed by a fine separation coupled to a sensitive and selective detector.

Figure 1 shows the relative errors of each step of the analytical procedure. The sample preparation represents $61 \%$ of total errors [16]. It is thus important to control this step which includes extraction and purification. Extraction is the limiting step. It must be complete for the studied compounds whatever the nature of the matrix.

The choice of the technique is the result of a compromise between efficiency and reproducibility of extraction, ease of procedure, with consideration of the cost, the time, the degree of automation and the security. We cannot expect that an extraction method is equally efficient for complex and variable matrices with very different interactions.

\section{Principles of extraction}

To model the extraction process, the matrix can be compared to a grain constituted of an impermeable core covered by a porous organic layer (Fig. 2). According to the kinetic model of Pawliszyn [17] (established for supercritical fluid extraction), the compounds, fixed to the surface of core, are

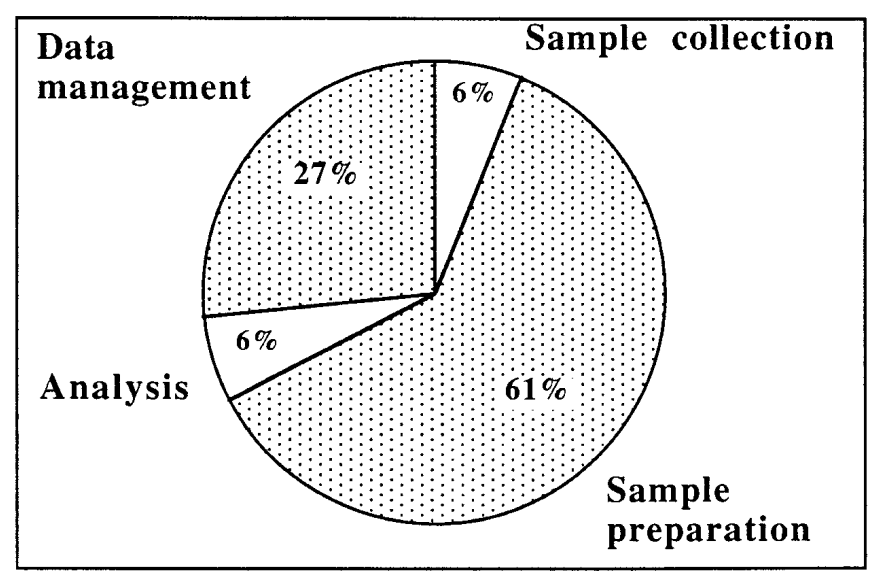

Fig. 1. Relative error of different steps for analytical procedure for organic compounds (from Major, 1991 [16]).

extracted in several steps: desorption from the matrix surface, diffusion in the porous organic layer up to the solvent and solubilisation in the solvent. The extraction recovery can be limited by one or several steps. The solubility is rarely the limiting factor if the solvent is well chosen. The desorption is the most important factor to consider. A quantitative extraction must overcome interactions between analytes and matrix. These interactions depend partly on the composition of the matrix. The contaminants of a soil can be associated with inorganic compounds (alumina, silica...) and/or to organic (humics and fluvics) active sites each one with different strength. Extraction of contaminants can be prevented by physical barriers: compounds can be localised in interstitial micropores in particles of soil or between clay plates, be covered by or associated with organic material or be covered by water droplets, which must be extracted to extract the analyte [18].

Organic contaminants are classically extracted by Soxhlet extraction. This method proceeds by iterative percolation of the sample by recondensed vapours of solvent. This method uses large quantities of solvent (about $500 \mathrm{~mL}$ ). The time of extraction can vary between 8 hours to 48 hours.

\section{Microwave heating}

\section{Microwave theory}

Microwaves cover a 3 order scale $(300 \mathrm{MHz}$ to $300 \mathrm{GHz}$, i.e. wavelength in air or vacuum between $1 \mathrm{~m}$ and $1 \mathrm{~mm}$ ) (Fig. 3). Microwaves are electromagnetic waves made up of two oscillating perpendicular fields: electrical field and magnetic field. Microwaves are used as information carriers or as energy vectors. This second application is the direct action of waves on material which is able to absorb a part of electromagnetic energy and to transform it into heat. Microwaves at $2450 \mathrm{MHz}$ are used in the microwave oven. This frequency corresponds to a wavelength of $12.2 \mathrm{~cm}$ and 


\section{Original articles}

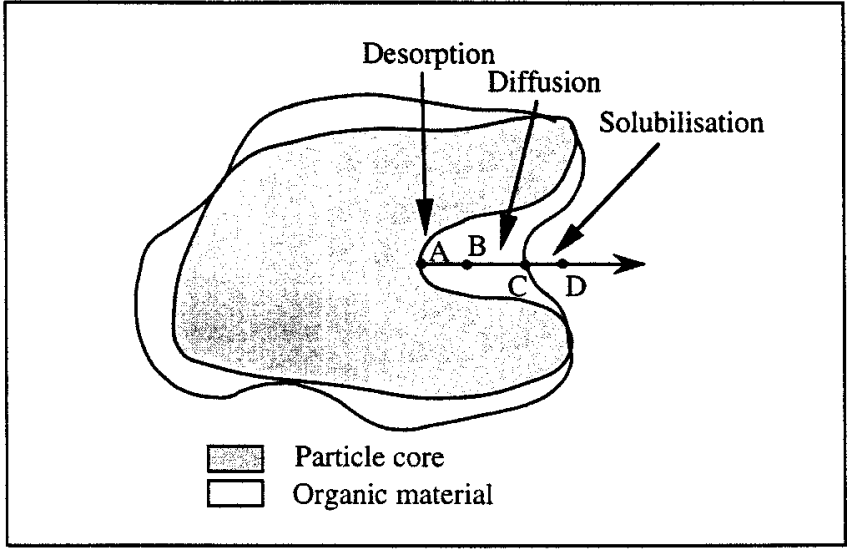

Fig. 2. The schematic representation of the individual steps in the extraction process (AB: desorption, $\mathrm{BC}$ : diffusion, $\mathrm{CD}$ : solubilisation) (from Pawliszyn, 1993 [17]).

an energy of $0.23 \mathrm{cal} / \mathrm{mol}(=0.94 \mathrm{~J} / \mathrm{mol})$. This frequency can only cause rotation of molecules. The electrical component of the wave changes $4.9 \times 10^{9}$ times per second. It generates a disorganised movement of polar molecules which are irradiated by microwaves. This disorganised agitation creates heat.

\section{Microwave heating}

The heat phenomenon is based on the interaction of the electrical field with compounds of a material. The transformation of electromagnetic energy in calorific energy occurs by two mechanisms: ionic conduction and dipole rotation. The ionic conduction generates heat due to the resistance of medium to ion flow. The migration of dissolved ions causes collisions between molecules because the direction of ions changes as many times as the field changes sign. The dipole rotation is related to alternative movement of polar molecules which try to line up with the electric field. Multiple collisions from this agitation of molecules generate energy release and therefore a temperature increase [19].

A release of heat is observed only if materials have dielectric losses or conducting losses under microwave irradiation. The absorbed energy depends on the factor of dissipation $\delta$ for which $\tan \delta=\varepsilon^{\prime \prime} / \varepsilon^{\prime}$, with $\varepsilon^{\prime}$ et $\varepsilon^{\prime \prime}$, the real and complex part of dielectric permittivity $\left(\varepsilon=\varepsilon^{\prime}-\mathrm{j} \varepsilon^{\prime \prime}\right)$. $\varepsilon^{\prime}$ is the dielectric constant, which expresses the capacity of a molecule to be polarised by an electric field. $\varepsilon^{\prime \prime}$ is dielectric loss factor which expresses the efficiency of transformation of electromagnetic energy into heat.

The compounds which have high dielectric losses are principally polar compounds. Dielectric constants of common solvents are summarised in table I [20]. One specificity of microwave heating is therefore the selectivity. The second specificity is that the temperature gradient is reversed compared to conventional heating and the heating is volumic (Fig. 4).

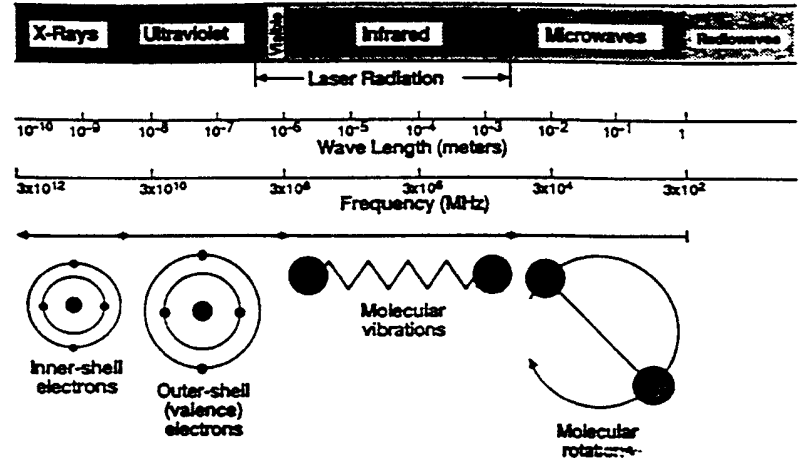

Fig. 3. Electromagnetic spectrum (from Neas and Collins, 1988 [9]).

Table I. Dielectric permittivity and dissipation factors for different solvents (at $3 \mathrm{GHz}$ and $25^{\circ} \mathrm{C}$ ) (from Zlotorzynski, 1995 [20]).

\begin{tabular}{lccc}
\hline & $\varepsilon^{\prime}$ & $\varepsilon^{\prime \prime}$ & $\tan \delta .10^{4}$ \\
\hline ice & 3.2 & 0.00288 & 9 \\
water & 76.7 & 12.0419 & 1570 \\
$\mathrm{NaCl} 0.1 \mathrm{~mol} / \mathrm{L}$ in water & 75.5 & 18.12 & 2400 \\
$\mathrm{NaCl} 0.5 \mathrm{~mol} / \mathrm{L}$ in water & 67 & 41.8756250 & \\
Methanol & 23.9 & 15.296 & 6400 \\
Ethanol & 24.3 & 1.625 & 2500 \\
$\mathrm{CCl}_{4}$ & 2.2 & 0.00088 & 4 \\
Heptane & 1.9 & 0.00019 & 1 \\
\hline
\end{tabular}

The temperature which is reached by solvent, can be higher than the boiling point. Baghurst and Mingos [21] have shown the superheating effects under microwaves. Solvents such as ethanol or dichloromethane can reach temperatures above their theoretical boiling point. The temperature can be more than $20{ }^{\circ} \mathrm{C}$ in some cases. They explain the origin of this phenomenon by the lack of nucleation sites.

The microwave heating has been used in digestion and synthesis with very good recoveries and a decrease of time of reaction. Different points of view have been proposed to explain the apparent acceleration. Some authors explain the efficiency of microwaves by their involvement in a phenomenon of activation [13,22]. Others deny the existence of any non-thermal microwave effect and explain the apparent accelerations merely by the fact that in the case of microwave heating, unlike conventional heating, the bulk temperature is no longer representative of the reaction conditions [23]. In extraction field, this controversy has not been evoked. Most of the studies have been performed under pressure and in this case the efficiency cannot be explained only by the heating mode. For extraction at atmospheric pressure, Letellier et al. [24] have not demonstrated any significant specific microwave effect for the studied cases (sediments and soils). The extraction acceleration [25] can be partly explained by the volumic character of the heating and 


\section{Original articles}

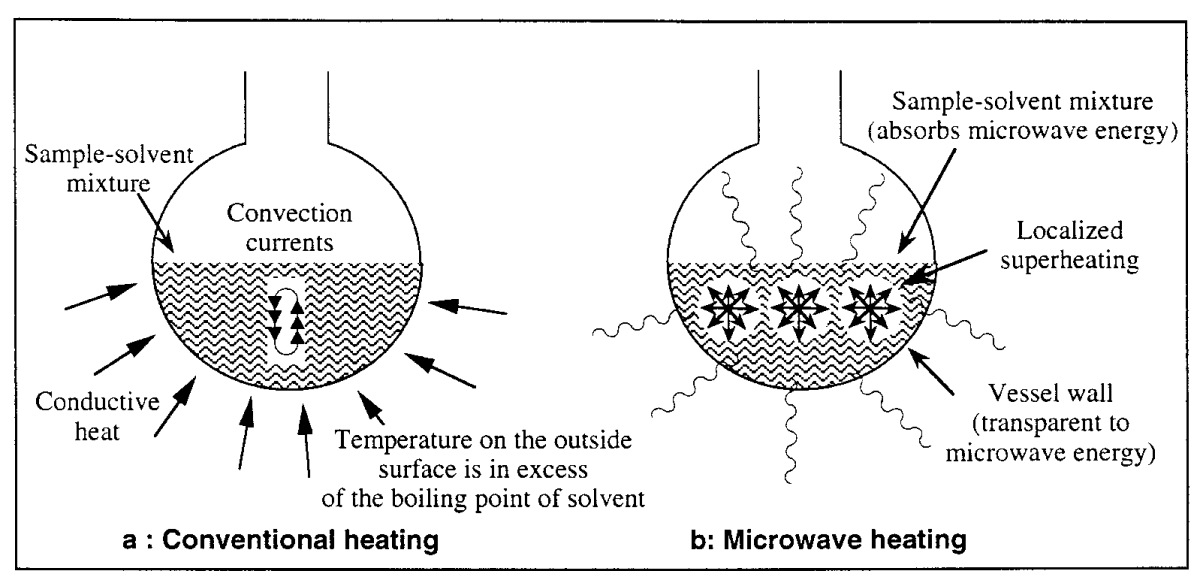

Fig. 4. Representation of the two heating modes: by convection (a) and by microwave energy (b) (from Neas and Collins, 1988 [19]). therefore by the specificity of heating (in the case of polyphasic systems) than by a specific activation by microwave at the molecular scale.

\section{Microwave oven}

Several distinctions between types of microwave ovens can be made.

Microwave ovens can have monomode or multimode cavity. The monomode cavity (Fig. 5a) can generate a frequency which excites only one mode of resonance. The sample can be placed on the maximum of the electrical field as the distribution of the field is known. The multimode cavity is large (Fig. 5b) and the incident wave is able to affect several modes of resonance. This superimposition of modes allows the homogenisation of field. Homogenisation systems such as rotating plate are added.

Microwave ovens can be operated under pressure (with or without regulation) or at atmospheric pressure. The first studies of organic compound extraction have been performed in domestic oven (multimode cavity) in closed vessels without pressure control. In the last few years, two types of apparatus dedicated to organic extraction have appeared. The first one, developed by CEM Corporation (MES 1000) (Matthews, NC, USA), is a multimode oven and the extractions are performed under controlled pressure (1 to $5 \mathrm{~atm}$ ) in closed bombs [26]. Twelve bombs can be placed on the rotating plate in the oven. One of them allows temperature and pressure control. Different powers are obtained with more or less long cycles of irradiation. The pressure allows temperatures above boiling points of the solvents to be reached. Table II shows temperatures obtained by solvents under $175 \mathrm{psig}\left(=12.10^{5} \mathrm{~Pa}\right)$ [27]. MILESTON (Sorisole, Italy) also supplies a multimode microwave oven (MLS1200 Mega).

The second type of oven has been developed by PROLABO (Soxwave 100) (Fontenay-sous-Bois, France) [28]. It works at atmospheric pressure in an open cell and uses focused microwaves. A reflux system is placed on open vessel. Irradiation is continuous. Power can be modulated (\% of full power). The field is homogeneous and reproducible.
Table II. Boiling temperatures and temperatures under microwave at 175 psig of different solvents (from Jassie, 1995 [27]).

\begin{tabular}{|c|c|c|}
\hline Solvent & $\begin{array}{c}\text { Boiling } \\
\text { temperature }{ }^{\circ} \mathrm{C}\end{array}$ & $\begin{array}{c}\text { Temperature } \\
\text { at } 175 \text { psig }\end{array}$ \\
\hline Dichloromethane & 39.8 & 140 \\
\hline Acetone & 56.2 & 164 \\
\hline Methanol & 64.7 & 151 \\
\hline Hexane & 68.7 & $\mathrm{nh}$ \\
\hline Ethanol & 78.3 & 164 \\
\hline Cyclohexane & 80.7 & $\mathrm{nh}$ \\
\hline Acetonitrile & 81.6 & 194 \\
\hline 2-Propanol & 82.4 & 145 \\
\hline Petrol ether & $35-80$ & $\mathrm{nh}$ \\
\hline Acetone/hexane (1/1), v/v) & 52 & 156 \\
\hline Acetone/cyclohexane $(70 / 30, \mathrm{~V} / \mathrm{V})$ & 52 & 160 \\
\hline Acetone/petrol ether $(1 / 1, \mathrm{v} / \mathrm{v})$ & 39 & 147 \\
\hline
\end{tabular}

$\mathrm{nh}=$ no heat under microwave.

One advantage of microwave heating is the absence of inertia. There is no temperature gradient and the temperature is homogeneous in the medium.

\section{Microwave assisted extraction}

\section{First developments}

The first publications which dealt with the efficiency of microwave heating for organic extraction appeared in 1986. Ganzler et al. [14,29] have developed extraction protocols for lipids, antinutritives and pesticides from soils, seeds, foods and feeds in a few millilitres of solvent, irradiated for $30 \mathrm{~s}$ up to 7 times in a domestic oven $(1140 \mathrm{~W})$. The sequential irradiation avoids a temperature increase of the medium. Polar compounds (pesticides and antinutritives) are extracted in methanol or in a mixture of methanol/water. Extraction kinetics have been studied. Only two irradiations are necessary to obtain the maximum recovery for pesticides. Antinutritives are sensitive to temperature and are often degraded by classical Soxhlet extraction. The method of 


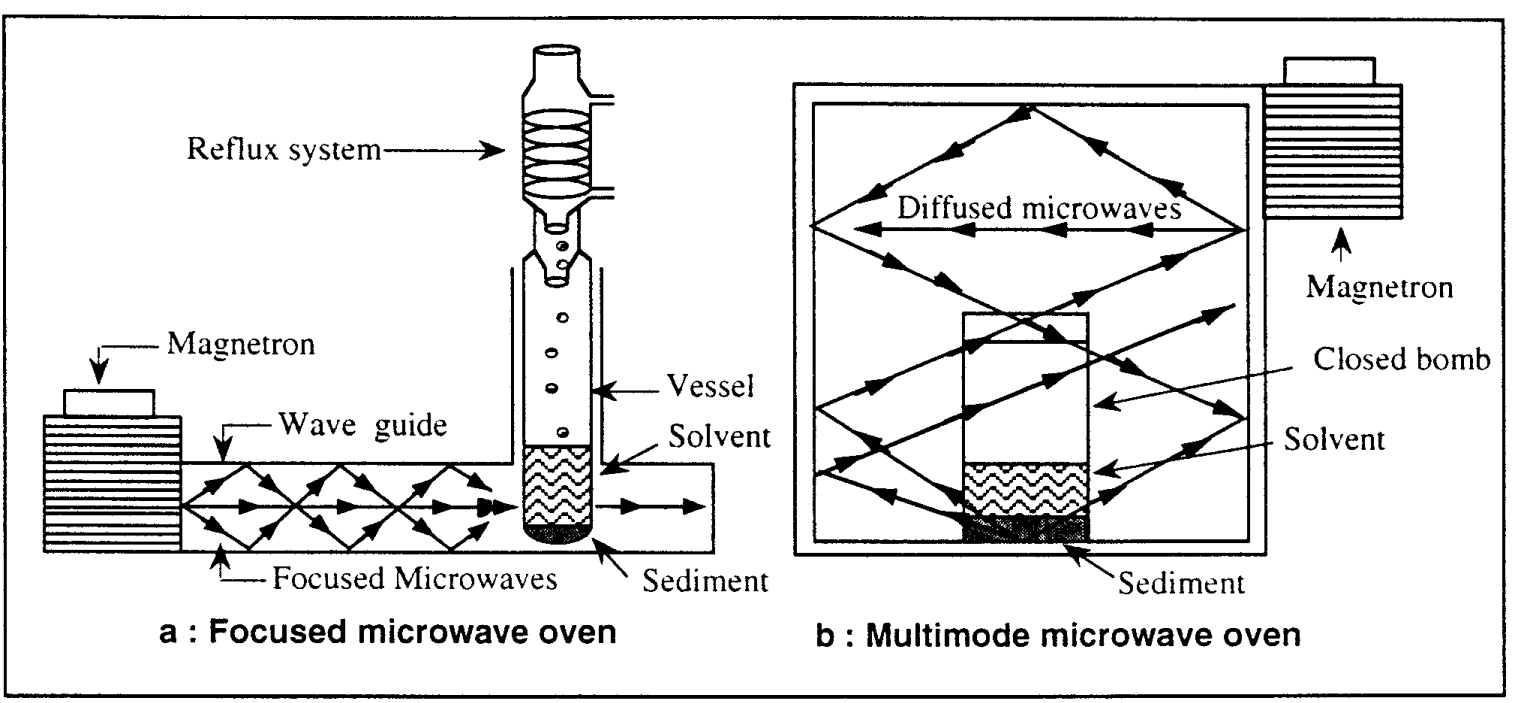

Fig. 5. Schematic view of focused microwave oven (a) and multimode microwave oven (b).

microwave assisted extraction is particularly suited for the study of thermolabile compounds. The recoveries are much higher because the temperature remains low.

Also in 1986, Lane and Jenkins [15] proposed the desorption of hydrocarbons from particulate matter by microwave irradiation with gas flow to replace extraction by solvent or desorption by infrared radiation which allows only superficial heating.

The recovery of essential oils is also one of the first applications in the organic extraction field. In 1989, Craverio et al. [30] have compared extraction by steam flow and microwave assisted extraction of fresh leaves of Lippia sidoides. The analysis of essential oils has shown no major difference in qualitative composition (presence of compounds) but has shown different relative percentages of some compounds. Extraction lasts only 5 minutes instead of 60 to 90 minutes. It uses an air flow and no solvent. The minimal quantity of matrix necessary is relatively low. Since 1991, the "VMHD" process (Vacuum Microwaves Hydrodistillation) has been patented by Archimex [31].

Paré et al. [25] have also developed an extraction process of natural products in water, soils, plants and animals (MAP $^{\mathrm{TM}}$ Microwave Assisted Process) in liquid and gas phases. This method enhances analytical capabilities such as selectivity and sensitivity, with similar or better linearity and reproducibility factors than traditional methods. The process has been patented in 1989 in Canada and then in other countries [32-34]. The extraction in liquid phase proceeds by heating of the sample placed in a transparent solvent which serves to solubilise extracted compounds and cools the heated matrix. Different examples have been shown [33]. Minced mint leaves are placed in hexane and irradiated $(600 \mathrm{~W})$ for $40 \mathrm{~s}$. The extraction recovery is comparable to that obtained with traditional distillation extraction for 2 hours. The composition of essential oils is different and is judged better with less undesirable compounds. The study has also shown interest for extraction of thermolabile compounds (essential oil of garlic). Other examples show that the recovery can be slightly lower but the quality of the product is better [33]. A comparative microscopic study has been performed on non treated mint leaves, which are extracted by microwave and by Soxhlet in hexane [25]. Essential oils are generally contained in secretory glands, localised in tissues or at the surface of the leaves. These pockets contain different contents of water. Microwaves interact selectively with water and cause localised heating. The result is a sudden non-uniform rise in temperature until the boiling point and even above. A dramatic expansion in volume within the system occurs. The internal pressure causes the rupture of the systems walls. The organic contents flow freely toward the relatively cool surrounding solvent which solubilises them rapidly. The diffusion of the solvent is not important, contrary to Soxhlet or distillation extraction. Owing to the migration of compounds directly in solvent, only the solubility is important to obtain a good recovery.

In 1993, Onuska and Terry [35] compared microwave assisted extraction of sediments, spiked with chlorinated pesticides and saturated with water with Soxhlet extraction and convection heating. Microwave assisted extraction at maximal power (non specified) for $30 \mathrm{~s}$ is repeated 5 times after each step of cooling in order that the solvent does not reach the boiling temperature. Microwave assisted extraction with a mixture of hexane/acetone gives a better recovery than Soxhlet extraction for 6 hours with hexane/acetone. Convection heating gives only recovery of $20 \%$ (non specified conditions). The maximum recovery is obtained for another sediment with $15 \%$ of matrix moisture (recovery close to $100 \%$ ) compared to a recovery of only about $15 \%$ when the matrix is dry. The stability of compounds has been tested. An irradiated pesticide solution is not degraded. 
Lopez-Avila et al. [36] are the first to test the extraction of organic contaminants with laboratory microwave oven dedicated to digestion (MSD 2000, CEM, USA). They have studied the extraction of PAHs, basic, neutral and acid priority pollutants in closed cells for different certified matrices (soils and sediments). Several parameters have been tested: temperature, irradiation time and matrix moisture. Their influences are discussed below.

Budzinski et al. [37,38] have tested the efficiency of focused microwave assisted extraction at atmospheric pressure (Maxidigest, Prolabo, France). A reflux system which is placed on the extraction tube allows the recondensation of solvent vapours. The preliminary tests have shown the potentials of this extraction method as alternative to Soxhlet extraction.

According to the first developments, two principles of extraction under microwaves exist:

- direct heating of the matrix which absorbs microwaves and which releases the analytes into the transparent cool dissolving solvent or,

- heating of polar solvent to reach the boiling point and to extract the compounds with hot solvent.

For the analysis of hydrophobic contaminants and moderately polar compounds in solid matrices, the second principle is the most used.

\section{Microwave assisted extraction in closed vessel}

Microwave assisted extraction of semi-volatile and nonvolatile compounds is generally performed with solvents, such as dichloromethane or a mixture like hexane/acetone, which are used for conventional methods with the condition that they are sufficiently polar to heat under microwaves. The irradiation lasts a few minutes and the volume of solvent is about $30 \mathrm{~mL}$ for 5 grams of sample. The temperature is linked to the pressure. The extraction is performed at about $100-140{ }^{\circ} \mathrm{C}$. The pressure is $1-5$ atm. Twenty minutes are necessary for cooling of the extract [26]. This technique can be applied to the extraction of polycyclic aromatic hydrocarbons (PAHs), total petroleum hydrocarbons (TPHs), polychlorobiphenyls (PCBs), pentachlorophenols, organochlorine and organophosphorus pesticides, triazine pesticides, fungicides, herbicides, phenolic compounds, neutral and basic priority pollutants, and chlorinated benzenes. Table III summarises the studies dealing with microwave assisted extraction in closed vessel specifying the type of apparatus, the studied compounds (semi-volatile and nonvolatile compounds) and the studied matrices.

\section{Influence of time}

According to the authors, the extraction time is not a significant factor for the organic compound extraction in environmental matrices. Lopez-Avila et al. [36] have tested the influence of extraction time $(5,10,20 \mathrm{~min})$ for PAH analysis from soil with a mixture of hexane/acetone at $115^{\circ} \mathrm{C}$.
The increase of extraction recovery with time is not significant; 5 minutes are sufficient. Barnabas et al. [39], Hasty and Revesz [40] and Chee et al. [41] have also shown that extraction time is not a significant parameter (respectively between 5 and 20 minutes for PAH extraction from a soil, between 5 and 30 minutes for total petroleum hydrocarbon extraction from a soil, and between 5 and 15 minutes for PAH extraction from a certified sediment).

\section{Influence of temperature}

The influence of temperature seems to depend on the matrix. Some studies have shown that the temperature is not a significant factor. Other studies have determined the optimal temperature around $100{ }^{\circ} \mathrm{C}$. Lopez-Avila et al. [36] have tested the influence of temperature on $\mathrm{PAH}$ extraction from a soil with a mixture of hexane/acetone. The increase of recovery is significant between ambient temperature, $80{ }^{\circ} \mathrm{C}$ and $115{ }^{\circ} \mathrm{C}$ (recoveries of 52,70 et $75 \%$ respectively). At $145{ }^{\circ} \mathrm{C}$ the recovery is comparable to that obtained at $115{ }^{\circ} \mathrm{C}$. For Chee et al. [41], the study by experimental design (between $115^{\circ} \mathrm{C}$ and $135^{\circ} \mathrm{C}$ ) of PAH extraction in certified matrices has shown that $115^{\circ} \mathrm{C}$ is the optimal temperature. Fish and Revesz [42] have tested the influence of temperature between 90 and $120{ }^{\circ} \mathrm{C}$ on the extraction recovery of a soil spiked with chlorinated pesticides. The best recoveries are obtained with $120{ }^{\circ} \mathrm{C}$. For triazine extraction from soils [43], the temperature is an important parameter and depends on the analyte polarity and on the nature of the soil. The extraction recoveries vary only by 5 to $10 \%$ around the optimum $\left( \pm 30{ }^{\circ} \mathrm{C}\right)$. A scale of $80-100{ }^{\circ} \mathrm{C}$ has been chosen, which is acceptable for all studied triazines in different soils. Hasty and Revesz [40] have determined the temperature of $150{ }^{\circ} \mathrm{C}$ as optimum (study between 125 and $160{ }^{\circ} \mathrm{C}$ ) for total petroleum hydrocarbon extraction in soil. Barnabas et al. [39] have shown that the temperature (between $40{ }^{\circ} \mathrm{C}$ and $120{ }^{\circ} \mathrm{C}$ ) is not a significant parameter for PAH extraction in soil.

\section{Influence of moisture}

The matrix moisture improves the extraction recovery in most of the case. The extraction of the most polar basic priority pollutants is improved with moisture according to Lopez-Avila et al. [44]. McMillin et al. [45] explain the better recovery of PCBs by microwave assisted extraction for moist matrix by the presence of water which allows a more rapid temperature increase of the matrix. The efficiencies of PAH extraction from dry or remoistened matrices (20\% of moisture) are the same according to Lopez-Avila et al. [36]. On the other hand, for organophosphorus and organochlorine pesticide extraction, the increase of recovery for a spiked soil is attributed to water presence in the matrix ( $2 \mathrm{~mL}$ of water for $5 \mathrm{~g}$ of matrix) [46].

\section{Influence of matrix nature}

The microwave assisted extraction seems to be not matrix dependent. The extraction recoveries are generally good 
Table III. References related to microwave assisted extraction in closed vessel of organic contaminants. CEM and Mileston apparatus are commercially available laboratory microwave ovens, Thoshiba, Sanyo and Kenmore apparatus are adapted domestic microwave ovens, (TPH: Total Petroleum Hydrocarbons, PUF: Polyurethane Foam).

\begin{tabular}{|c|c|c|c|c|c|}
\hline Authors & Year & Apparatus & Compounds & Matrices & Reference \\
\hline Ganzler et al. & 1986 & Thoshiba & pesticides & soil & 14 \\
\hline Lane et al. & 1986 & Lab. oven & PAHs & coal & 15 \\
\hline Ganzler et al. & 1987 & Thoshiba & pesticides & soil & 29 \\
\hline Onuska et al. & 1993 & Kenmore & organochlorine pesticides & sediment & 35 \\
\hline Steinheimer & 1993 & CEM & $\begin{array}{c}\text { triazines } \\
\text { tring }\end{array}$ & soil, water & 70 \\
\hline Lopez-Avila et al. & 1994 & CEM & $\begin{array}{l}\text { PAHs, phenols, organochlorine pesticides, } \\
\text { neutral and basic compounds }\end{array}$ & soi, sediment & 36 \\
\hline Barnabas et al. & 1995 & CEM & PAHs & soil & 39 \\
\hline Hasty et al. & 1995 & CEM & TPH & soil & 40 \\
\hline Jassie & 1995 & CEM & TPH & soil & 27 \\
\hline Lopez-Avila et al. & 1995 & CEM & organochlorine and organophosphorus pesticides, arochlors & soil & 48 \\
\hline Lopez-Avila et al. & 1995 & CEM & organochlorine pesticides, phenols & soil & 46 \\
\hline Lopez-Avila et al. & 1995 & CEM & PCBs & soil, sediment & 47 \\
\hline Chee et al. & 1996 & CEM & PAHs & sediment & 41 \\
\hline Enders et al. & 1996 & CEM & PAHs, PCBs & soil, sludge & 56 \\
\hline Fish et al. & 1996 & CEM & organochlorine pesticides & soil & 42 \\
\hline Lao et al. & 1996 & Sanyo/CEM & PAHs & PUF & 51 \\
\hline Lopez-Avila et al. & 1996 & CEM & $\begin{array}{l}\text { PAHs, phenols, organochlorine pesticides, } \\
\text { neutral and basic compounds }\end{array}$ & soil, sediment & 44 \\
\hline Molins et al. & 1996 & CEM & triazines & soil & 53 \\
\hline Stout et al. & 1996 & CEM & herbicides & soil & 52 \\
\hline Enders et al. & 1997 & CEM & PCBs & soil, sludge & 57 \\
\hline Frost et al. & 1997 & Milestone & fungicides & soil & 49 \\
\hline Hoogerbrugge et al. & 1997 & CEM & triazines & soil & 43 \\
\hline Li et al. & 1997 & CEM & PAHs, PCBs, neutral and basic compounds, phenols, pesticides & sediment, soil & 54 \\
\hline Llompart et al. & 1997 & CEM & phenolic compounds & soil & 50 \\
\hline Llompart et al. & 1997 & CEM & phenolic compounds & soil & 71 \\
\hline McMillin et al. & 1997 & CEM & organochlorine pesticides, PCBs & soil & 45 \\
\hline
\end{tabular}

compared to Soxhlet extraction for the majority of compounds. Some low extraction recoveries can be obtained for the less stable compounds with some matrices. LopezAvila et al. [36] have performed PAH extraction of six certified matrices with the same procedure. The extraction recoveries vary between $57 \%$ and $99 \%$. The PCB extraction has been tested by the same team on different spiked matrices (topsoil, claysoil, sand) [47]. The extraction recoveries are above $70 \%$ except for the claysoil for which the recovery is a little lower (62\%). Lopez-Avila et al. [48] have also tested extraction of organochlorine and phenolic compounds on different soils (sand, claysoil, topsoil, organic compost, soil with 5\% humic acid). The majority of compounds are well extracted with recoveries above $70 \%$. Some compounds have nevertheless low recoveries such as dinitrophenol (about 30\%), but it is not so low for the sand (69\%). Frost et al. [49] have compared the efficiency of microwave assisted extraction of fungicides in spiked soils with Soxhlet extraction. The extraction recoveries are good for a sandyclay soil $(91 \%)$ but the recoveries are low for the extraction of a sandy soil containing more organic matter $(50 \%)$. Llompart et al. [50] have studied the influence of charcoal content in a soil on the extraction recovery of phenolic compounds. The extraction recoveries are good whatever the charcoal percentage, except for o-cresol for which the extraction recovery decreases with the increase of charcoal content.

Polyurethane foam, used for air particulate matter sampling can also be extracted by microwave assisted extraction. In a transparent solvent such as cyclohexane, the microwave energy is absorbed by the foam. The extraction recoveries are generally higher than those obtained by mechanical extraction or Soxhlet extraction [51].

\section{Influence of nature and volume of solvent}

The solvents are generally the same than for Soxhlet extraction and depends on the studied analytes.

Lopez-Avila et al. [36] have tested the required time for different solvents to reach boiling temperature according to the volume and the matrix. The common solvents heat in a few minutes (dichloromethane, toluene/methanol, hexane/ methanol...). When a larger solvent volume is used, the heating is faster. The matrix presence has little effect on the temperature of the medium. The number of samples in the oven has an effect on the time of heating until the maximum temperature since the global power is kept constant. Indeed, when the number of samples increases, the power for each sample decreases. 
The polar and basic priority pollutants have low extraction recoveries with a mixture of hexane/acetone $(1 / 1, \mathrm{v} / \mathrm{v})$ for a spiked matrix according to Lopez-Avila et al. [36]. A more polar solvent such as acetonitrile allows better recoveries at 50 and $115{ }^{\circ} \mathrm{C}$. For the extraction of a certified sediment (SRM 1941a, NIST), better recoveries are obtained with dichloromethane that with a mixture of hexane/acetone $(1 / 1, v / v)$, but the results remain lower than certified values [44]. Barnabas et al. [39] have shown that the microwave assisted extraction recovery of PAHs is satisfying with dichloromethane or a mixture of hexane/acetone $(2 / 8, \mathrm{v} / \mathrm{v})$ by comparison with Soxhlet extraction. The extraction recovery can be improved with the use of pure acetone for one soil but remains the same for other soils.

Chee et al. [41] have tested the efficiency of different solvents by experimental design for PAH extraction. The mixture of acetone/hexane $(1 / 1, \mathrm{v} / \mathrm{v})$ gives the best results. Fish and Revesz [42] have tested two mixtures of solvents for the extraction of chlorinated pesticides: acetone/hexane (1/1, $\mathrm{v} / \mathrm{v})$ and acetone/hexane $(3 / 2, \mathrm{v} / \mathrm{v})$ which is the azeotrope composition used for Soxhlet extraction. The extraction recoveries are already good with the $1 / 1$ mixture but can be improved with a $3 / 2$ mixture. For Stout et al. [52], the choice of solvent is a compromise between a good extraction recovery and a sufficient extraction selectivity concerning coextracted compounds to avoid an advanced purification step. But the choice depends on matrix nature and on the difficulty to extract the analyte. Molins et al. [53] have tested different solvent compositions (acetonitrile/water (70/30, $\mathrm{v} / \mathrm{v})$, dichloromethane/water $(50 / 50, \mathrm{v} / \mathrm{v})$, dichloromethane/ methanol $(90 / 10, v / v))$ for triazine extraction in soils and have shown the efficiency of the mixture dichloromethane/ methanol $(9 / 1, \mathrm{v} / \mathrm{v})$. Jassie [27] has obtained better extraction recoveries for total petroleum hydrocarbons in soils with a mixture of hexane/acetone $(1 / 1, \mathrm{v} / \mathrm{v})$ than with dichloromethane or a mixture of acetone/dichloromethane $(1 / 1, v / v)$.

The study of influence of solvent volume by experimental design has shown that this factor is not significant for PAH extraction in sediment and soil [39-41].

\section{Stability of compounds}

Organic compounds seem to be stable under microwave irradiation in experimental conditions in solvent medium (without matrix) even for labile compounds. Some degradation can occur in the presence of matrix.

Lopez-Avila et al. [47] have tested the stability of commercial mixture of PCBs (Aroclors) under microwaves with or without matrix (dry or moist) at different temperatures (50 and $145{ }^{\circ} \mathrm{C}$ ) until 20 minutes. The obtained recoveries are comparable to those obtained after evaporation under nitrogen blowdown. Fish and Revesz [42] have tested the stability of chlorinated pesticides which are fragile at high temperatures, such as DDT, lindane, heptachlor, aldrin, dieldrin, endrin. No significant degradation and no adsorption on Teflon bombs has been noted in extraction conditions with- out matrix. Li et al. [54] have also shown no significant degradation for endrin and DDT under microwaves. LopezAvila et al. [36] have tested the stability of different compounds in extraction conditions without matrix and with a spiked soil (475 watts, hexane/acetone $(1 / 1, \mathrm{v} / \mathrm{v}), 10 \mathrm{~min}-$ utes, $115^{\circ} \mathrm{C}$ ). For phenols, organochlorine pesticides, PAHs, neutral and basic priority pollutants, there is no degradation in solvent medium. On the other hand, in the presence of matrix, some compounds can be degraded probably by catalytic reactions (extraction recoveries of about $80 \%$ for isomers of hexachlorobenzene; extraction recoveries under $20 \%$ for dinitrophenols) or lost for the most volatile compounds (low molecular weight PAHs, chlorobenzenes) [36]. Hwang and Vanderveen [55] have shown reactions of PAHs during microwave assisted extraction with dichloromethane of coal ash samples under pressure. Some chlorinated species (chlorophenanthrene and chloronaphthalene) were observed at temperatures above $80{ }^{\circ} \mathrm{C}$.

\section{Comparison with other extraction methods}

Lopez-Avila et al. [48] have compared microwave assisted extraction under pressure with sonication and Soxhlet extraction for matrices spiked with organochlorine pesticides and for a certified matrix for phenols. Microwave assisted extraction gives better extraction recoveries. Different compounds (PAHs, phenols, chlorobenzenes) are extracted from the matrix in the same proportions as for Soxhlet extraction, but with lower standard deviations [44]. Enders et al. [56,57] have tested the PCB extraction from soils and sewage sludges and have obtained higher concentrations than those obtained by Soxhlet and supercritical fluid extraction. According to Chee et al. [41], the PAH extraction by microwaves of certified materials gives comparable results to those obtained by Soxhlet extraction. McMillin et al. [45] have obtained better extraction recoveries for PCBs in sediments with microwaves than with Soxhlet or ultrasound techniques. However, extracts are less clean than those obtained by classical methods and require the addition of a purification step [45].

\section{Focused Microwave assisted extraction at atmospheric pressure}

Focused microwave assisted extraction at atmospheric pressure is also generally performed with solvents which are used for conventional methods with the condition that they are sufficiently polar to heat under microwaves. The irradiation time is a few minutes and the volume of solvent is a few millilitres. The maximal temperature is close to the boiling point (only a few ${ }^{\circ} \mathrm{C}$ more). It does not need a long cooling time. A cartridge can be used in the vessel under microwaves. After the extraction step, the cartridge can be raised above the microwave field. This method does not need a filtering step. The reflux of solvent rinses the cartridge. The extract can be reconcentrated to a few millilitres under microwaves.

This technique has been applied up to now to the extraction of polycyclic aromatic hydrocarbons (PAHs), aliphatic 
hydrocarbons, polychlorobiphenyls (PCBs), organochlorine pesticides, triazine pesticides in soils, sediments, air particulate matter and source rocks (Tab. IV). Microwave energy has also been used for the extraction of PAHs in biological tissues with alcoholic potassium hydroxyde [38]. Budzinski et al. [58] have developed a protocol of extraction coupled to purification (degradation of interfering organic matter with sulfuric acid) under microwaves for the analysis of PAHs and PCBs in sediments. Only one extraction is required for the analysis of the two classes of compounds. Garcia-Ayuso et al. [59] have developed a microwave assisted Soxhlet prototype using conventional Soxhlet glassware. They couple the advantage of Soxhlet which proceeds with fresh solvent and the advantage of microwave which allows a direct interaction of the microwave energy on the matrix. The sample cartridge is irradiated at the required interval while fresh solvent drips on and passes through the solid sample. Microwave energy is used to break analytematrix bonds.

Table IV also resumes the studies dealing with focused microwave assisted extraction at atmospheric pressure and specifies the type of apparatus, the studied compounds (semi-volatile and non-volatile compounds) and the studied matrices.

\section{Influence of time}

Budzinski et al. [60] have tested the influence of irradiation time on the extraction of PAHs in a certified sediment (SRM 1941a). There is no significant difference between 5 and 30 minutes. A time of 10 minutes has been chosen to insure a safety margin for matrices difficult to extract. Letellier et al. [61] have performed an experimental design and has shown that extraction time is not an influent factor between 2 to 10 minutes for the extraction of PAHs from a natural sediment.

\section{Influence of power}

Budzinski et al. [60] have tested the influence of power irradiation on the extraction of PAHs in a certified sediment
(SRM 1941a) between $30 \mathrm{~W}$ (the minimum delivered by the system) and $210 \mathrm{~W}$ (the maximum temperature below which there is no bumping phenomenon). There is no significant difference and $30 \mathrm{~W}$ is chosen because it allows energy saving and insures safer implementation of the extraction. Letellier et al. [61] have performed an experimental design and have shown that the irradiation power (between 20 and $140 \mathrm{~W}$ ) has an effect on the extraction efficiency of PAHs from natural sediment when the matrix is dry and is not influential when the matrix is moist.

\section{Influence of solvent nature}

Budzinki et al. $[38,60]$ have tested the efficiency of different solvents for the extraction of PAHs from sediments (dichloromethane, dichloromethane/toluene $(1 / 1, \mathrm{v} / \mathrm{v})$, acetone/hexane $(1 / 1, \mathrm{v} / \mathrm{v}))$. There is no significant difference considering the standard deviations. Dichloromethane is chosen as it is easy to remove during reconcentration steps due to its low boiling point. Letellier et al. [61] have tested the efficiency of dichloromethane and a mixture of heptane/ethanol $(80 / 20, \mathrm{v} / \mathrm{v})$. They have shown that the mixture of heptane/ethanol is a good alternative to dichloromethane which is toxic and for which the use may be forbidden in the next few years.

Dupeyron et al. [62] have obtained better extraction recoveries with dichloromethane/acetone $(1 / 1, \mathrm{v} / \mathrm{v})$ than dichloromethane for the low molecular weight PAHs from soil.

\section{Influence of matrix nature}

Letellier et al. and Budzinski et al. [63-66] have applied the focused microwave assisted extraction to several matrices (natural or certified sediments, soils, source rocks, air particulate matter...) for analysis of PAHs, PCBs, pesticides, $n$ alkanes. The extraction is efficient with recoveries above $70 \%$ compared to Soxhlet concentration and/or certified values for different classes of compounds and different matrices of different composition, different origins of contamination and different levels of contamination.

Table IV. References related to focused microwave assisted extraction at atmospheric pressure of organic contaminants. Prolabo apparatus are commercially available laboratory microwave ovens.

\begin{tabular}{|c|c|c|c|c|c|}
\hline Authors & Year & Apparatus & Compounds & Matrices & Reference \\
\hline Budzinski et al. & 1995 & Prolabo & PAHs & sediment & 37 \\
\hline Budzinski et al. & 1995 & Prolabo & PAHs, PCBs & sediment & 64 \\
\hline Budzinski et al. & 1996 & Prolabo & PAHs & sediment, atmospheric particles, soil, mussel & 38 \\
\hline Budzinski et al. & 1996 & Prolabo & HAPs, PCBs & sediment, soil, mussel & 65 \\
\hline Budzinski et al. & 1997 & Prolabo & PAHs, PCBs & sediment & 58 \\
\hline Dupeyron et al. & 1997 & Prolabo & PAHs & soil & 62 \\
\hline Lettelier et al. & 1997 & Prolabo & PAHs & soil, sediment, atmospheric particles & 63 \\
\hline Garcia-Ayuso et al. & 1998 & Prolabo & PAHs, alkanes, herbicides & soil & 59 \\
\hline Letellier et al. & 1998 & Prolabo & PAHs, PCBs, alkanes, pesticides & sediment, soil, atmospheric particles & 66 \\
\hline Budzinski et al. & in press & Prolabo & PAHs & sediment, soil, atmospheric particles & 60 \\
\hline Letellier et al. & 1999 & Prolabo & PAHs & sediment & 61 \\
\hline
\end{tabular}




\section{Original articles}

The coefficients of variation are equal to or lower than those obtained by Soxhlet extraction. This method is not matrixdependent.

\section{Influence of moisture}

Budzinski et al. [38] have compared the efficiency of PAH extraction in dry and moist certified sediment SRM 1941a (20\% of moisture). The mean recovery compared to certified values increases from $85 \%$ for the dry sediment to about $100 \%$ for the moist sediment. The influence of percentage of water added to dry matrix has been studied more accurately (moisture between $20 \%$ and 100\%) [60]. 30\% of moisture gives the best recovery for the PAH extraction from sediment. A too high percentage of water inhibits diffusion of the solvent and the analytes and gives low recoveries. The extraction of other matrices has been performed in the same condition with $30 \%$ of moisture. The recoveries for PAH extraction are increased owing to the moisture and the recoveries are close to $100 \%$ for all the studied matrices.

Dupeyron et al. [62] have tested the effect of water added to the matrix or to the solvent with dichloromethane and a mixture of dichloromethane/acetone (1/1, v/v). For dichloromethane, the recoveries are lower when the moisture is added directly to the matrix because there is a problem of miscibility and water prevents the diffusion of analytes and solvent. When the solvent is moistened (water added to the solvent), the effect is positive for low molecular weight PAHs but negative for the high molecular weight PAHs. For the mixture of dichloromethane/acetone $(1 / 1, \mathrm{v} / \mathrm{v})$, the effect of moisture added to the matrix is positive. Acetone allows a better miscibility of dichloromethane with water. The recoveries are better and the standard deviations are lower than with the same solvent without moisture.

\section{Stability of compounds}

The stability of PAHs under focused microwaves (dichloromethane, $30 \mathrm{~W}$, until 40 minutes) without matrix has been checked [37]. No degradation or loss of compounds has been noted. No degradation of organochlorine pesticides in the extraction conditions (dichloromethane, $30 \mathrm{~W}, 10 \mathrm{~min}$ utes) without matrix has been noted even for the more sensitive compounds (DDT, dieldrin, heptachlor epoxide...) [66].

\section{Extraction of volatile compounds}

Table $\mathrm{V}$ resumes the studies dealing with the microwave assisted extraction of volatile compounds with the type of apparatus, the studied compounds and the studied matrices.

Microwave energy can substitute traditional techniques such as liquid-liquid extraction or headspace for extraction of volatile compounds in water. Onuska and Terry [67] have tested PCB extraction from water by microwave heating in presence of salts and organic solvent for 2 minutes at full power $\left(70{ }^{\circ} \mathrm{C}\right)$ in closed cells. The presence of salts allows a more rapid heat transfer owing to ion presence in solution. The same team [68] has performed extraction of chlorobenzene from water by helium purge for 20 minutes under microwaves. Paré, et al. [25,33] have tested the extraction of volatile compounds by headspace from liquid and solid samples such as water, gel, creams... The microwave assisted extraction lasts $40 \mathrm{~s}$ at $500 \mathrm{~W}$ compared to $30 \mathrm{~min}$ at $80{ }^{\circ} \mathrm{C}$ with traditional headspace. The microwave heating allows a better recovery and a better sensibility than headspace and a good linearity. The response for aromatic compounds is improved by a factor of 5 and for aliphatic compounds by a factor of 2 to 6 . This method generates less discrimination for high molecular weight compounds because the important parameter is not vapour pressure such as classical extraction by headspace [69]. The evaporation level of volatile compounds under microwave is principally governed by the temperature of the liquid phase.

\section{Conclusions: Advantages of microwave assisted methods compared to conventional techniques (See Tab. VI)}

Soxhlet extraction is the most used technique in the field of organic compound extraction from solid samples. This method allows the extraction of a large quantity of matrix up to $100 \mathrm{~g}$ and does not need a filtering step. The material investment is not high (16 $200 \mathrm{FF}$ for 6 Soxhlet according to the Prolabo catalogue 98/99 (Fontenay-sous-Bois, France)), but the quantities of solvent are very high (about $500 \mathrm{~mL}$ ). Another drawback of this method is the long extraction time (up to 48 hours) (Tab. VI).

Table V. References related to microwave assisted extraction of volatile organic compounds (VOC) (laboratory oven is a non specified system, CEM apparatus is a commercially microwave oven. Kenmore is a domestic adapted microwave oven).

\begin{tabular}{lccccc}
\hline Authors & Year & Apparatus & Compounds & Matrices & Reference \\
\hline Paré et al. & 1994 & Laboratory oven & VOCs & water & 25 \\
Paré et al. & 1995 & CEM & VOCs & water & water \\
Onuska et al. & 1995 & Kenmore & PCBs & water & 67 \\
Onuska et al. & 1995 & Kenmore & Labinated benzenes & water & 69 \\
Paré et al. & 1997 & Laboratory oven & VOCs & 73 \\
Paré et al. & 1997 & Laboratory oven & & soil \\
\hline
\end{tabular}


The microwave assisted extraction in a closed vessel is fast and uses low quantities of solvent. One of the main advantages is the possibility to perform the extraction of several samples at the same time. This method requires cooling time and a filtering step. The temperatures attained are above boiling point which can be a problem for sensitive compounds. The material investment is quite high (about 180 000 FF for MSP 1000 (CEM) according to the Roucaire catalogue 1998 (Courtaboeuf, France) and about 135000 FF for MLF 1200 Mega (Milestone) according to the Fisher catalogue 1998 (Elancourt, France)).

The focused microwave assisted extraction at atmospheric pressure is fast and uses low quantities of solvent as for microwave assisted extraction in closed vessel. The work at atmospheric pressure is secure. It is possible to couple filtering owing to a cartridge and reconcentration under microwaves. The material investment is moderately high (69 000 FF for the Soxwave 3.6 (Prolabo) according to the PROLABO catalogue 98/99 (Fontenay-sous-Bois, France)). The drawback is that only three extractions at a time can be performed.

The efficiencies and reproducibilities of the two methods are satisfying for different matrices such as sediment, soil, atmospheric particles and for analysis of organic contaminants such as polycyclic aromatic hydrocarbons, polychlorobiphenyls, pesticides, herbicides, phenols... These microwave assisted methods at atmospheric pressure or in closed cell seem to be very good alternatives to Soxhlet extraction.

\section{Acknowledgements}

S. Thompson is thanked for her careful reading of the manuscript and J.L. DiMartino for interesting technical discussions and ideas about microwave extraction.

\section{References}

1. Soxhlet, F. Dingers Polytech. J. 1879, 232, 461.

2. Wise, S. A.; Schantz, M. M.; Benner, B. A.; Hays, M. J.; Schiller, S. B. Anal. Chem. 1995, 67, 1171-1178.

3. Schantz, M. M.; Parris; Kurz, J.; Ballschmiter, K.; Wise, S. A. Fresenius J. Anal. Chem. 1993, 346, 766-778.

4. Chaudot, X; Tambuté, A.; Caude, M.; Analusis 1997, 25, 8196.

5. Hawthorne, S. B. Anal. Chem. 1990, 62/11, 633A-642A.

6. Chester, T. L.; Pinkston, J. D.; Raynie, D. E.; Anal. Chem. 1994, 66, 106R-130R.

7. Berteaud, A. J.; Delmotte, M. La recherche 1993, 24, 287-294.

8. Samra, A. A.; Morris, J. S.; Koirtyohann, S. R. Anal. Chem. 1975, 47, 1475-1477.

9. Kingston, H. M.; Jassie, L. B. Introduction to microwave sample preparation, theory and pratice, American Chemical Society: Washington D.C., USA, 1988.

10. Smith, F. E.; Arsenault, E. A. Talanta 1996, 43, 1207-1268.

11. Gedye, R.; Smith, F.; Westaway, K.; Ali, H.; Baldisera, L.; Laberge, L.; Roussel, J. Tetrahedron Lett. 1986, 27, 279.

12. Giguere, R. J.; Bray, T. L.; Duncan, S. M.; Majetich, G. Tetrahedron Lett. 1986, 27, 4945.

13. Loupy, A. Spectra Anal. 1993, 175, 33-38.

Table VI. Parameters, advantages and drawbacks of Microwave Assisted extraction in closed vessel (MAE), Focused Microwave assisted extraction at atmospheric pressure (FMW) and Soxhlet extraction (BP: boiling point; a according to Fisher catologue 1998, ${ }^{\mathrm{b}}$ according to Roucaire catologue $1998,^{c}$ according to Prolabo catalogue 1998).

\begin{tabular}{|c|c|c|c|}
\hline Parameters & $M A E$ & $F M W$ & Soxhlet \\
\hline Examples of solvent & $\begin{array}{l}\text { dichloromethane } \\
\text { acetone/hexane }\end{array}$ & $\begin{array}{l}\text { dichloromethane } \\
\text { ethanol/heptane }\end{array}$ & $\begin{array}{l}\text { dichloromethane } \\
\text { acetone/hexane }\end{array}$ \\
\hline Volume & $30 \mathrm{~mL}$ & $30 \mathrm{~mL}$ & $300 \mathrm{~mL}$ \\
\hline Sample amount & $1-10 \mathrm{~g}$ & $1-50 \mathrm{~g}$ & $10-100 \mathrm{~g}$ \\
\hline Number of sample & 1 to 12 & 1 to 3 & 1 to 6 \\
\hline Vessel & Téflon 120 mL & quartz $100 \mathrm{~mL}$ & glass $500 \mathrm{~mL}$ \\
\hline Temperature & $40-150{ }^{\circ} \mathrm{C}(>\mathrm{BP})$ & $\mathrm{BP}$ & $\mathrm{BP}$ \\
\hline Pressure & $1-5 \mathrm{~atm}$ & ambient & ambient \\
\hline Time & $5-15 \mathrm{~min}$ & $10 \min$ & $8-48 \mathrm{~h}$ \\
\hline Time of cooling & $20 \min$ & $5 \mathrm{~min}$ & \\
\hline Power & $950 \mathrm{~W}$ & $300 \mathrm{~W}$ & \\
\hline Filtration & Filtration & possibility of cartridge & cartridge \\
\hline Price & $\begin{array}{l}135000 \mathrm{FF}^{\mathrm{a}} \\
180000 \mathrm{FF}^{\mathrm{b}}\end{array}$ & $69000 \mathrm{FF}^{\mathrm{c}}$ & $16200 \mathrm{FF}^{\mathrm{c}}$ \\
\hline Advantages & $\begin{array}{l}\text { - several samples } \\
\text { - low quantity of solvent } \\
\text { - low extraction time }\end{array}$ & $\begin{array}{l}\text { - security } \\
\text { - low quantity of solvent } \\
\text { - low extraction time } \\
\text { - coupled reconcentration }\end{array}$ & - low cost \\
\hline Drawbacks & $\begin{array}{l}\text { - required filtration } \\
\text { - time of cooling }\end{array}$ & - three samples & $\begin{array}{l}\text { - handling } \\
\text { - large quantity of solvent } \\
\text { - large extraction time }\end{array}$ \\
\hline
\end{tabular}




\section{Original articles}

14. Ganzler, K.; Salgo, A.; Valko, K. J. Chromatogr. 1986, 371, 299-306.

15. Lane, D.; Jekins, S. W. D. Polynucl. Aromat. hydrocarbons: Chem., Charact. Carcinog., Int. Symp., 9th. 1986, 437-449.

16. Majors, R. E. $L C / G C$ 1991, $9 / 1,16-20$.

17. Pawliszyn, J. J. Chromatogr. Sci. 1993, 31, 31-37.

18. Hawthorne, S. B.; Miller, D. J.; Budford, M. D.; Langenfeld, J. J.; Eckert-Tilotta, S.; Louie, P. K. J. Chromatogr. A 1993, 642, 301-317.

19. Neas, E. D.; Collins, M. J. Introduction to microwave sample preparation. American Chemical Society: Washington D.C., 1988, Chap. 2, 7-32.

20. Zlotorzynski, A. Critical Rev. Anal. Chem. 1995, 25, 43-76.

21. Baghurst, D. R.; Mingos, D. M. P. J. Chem. Soc. Chem. Comm. 1992, 674-677.

22. Lewis, D. A.; Summers, J. D.; Ward, T. C.; McGrath, J. E. J. Polym. Sci. A: Polym. Chem. 1992, 30, 1647-1653.

23. Laurent, R.; Laporterie, A.; Dubac, J.; Berlan, J.; Lefeuvre, S.; Audhuy, M. J. Org. Chem. 1992, 57, 7099-7102.

24. Letellier M. Ph. D. Thesis, University of Bordeaux, Oct. 1998.

25. Paré, J. R. J.; B,langer, J. M. R.; Stafford, S. S. Trends Anal. Chem. 1994, 13, 176-184.

26. Renoe, B. W. American Lab. 1994, 8, 34.

27. Jassie, L. Int. Lab. News 1995, April, 18.

28. Technical note of SOXWAVE 100, 1996, Prolabo, Fontenaysous-Bois, France.

29. Ganzler, K.; Salgo, A. Z. Unters. Forsch. 1987, 184, 274-276.

30. Craverio, A. A.; Matos, F. J. A.; Alenca, J. W.; Plumel, M. M. Flavour and Flagrance J. 1989, 4, 43-44.

31. Mengal, P.; Mompon, B. 1993 French Patent, No. 9305810.

32. Paré, J. R. J.; Sigouin, M.; Lapointe, J. 1991 US Patent 5002 784 March 1991.

33. Paré, J. R. J.; Sigouin, M.; Lapointe, J. 1991 European patent request, No. 0398798.

34. Paré, J. R. J. 1995 US Patent 5377426 January 1995.

35. Onuska, F. I.; Terry, K. A. Chromatographia 1993, 36, 191194.

36. Lopez-Avila, V.; Young, R.; Beckert; W. F. Anal. Chem. 1994, 66, 1097-1106.

37. Budzinski, H.; Papineau, A.; Baumard, P.; Garrigues, P. Comptes rendus de l'académie des sciences de Paris 1995, 321, 69-76.

38. Budzinski, H.; Baumard, P.; Papineau, A.; Wise, S.; Garrigues, P. Polycyclic Aromatic Compounds 1996, 9, 225-232.

39. Barnabas, I. J.; Dean, J. R.; Fowlis, I. A.; Owen, S. P. Analyst. 1995, 120, 1897-1904.

40. Hasty, E.; Revesz, R. American Lab. 1995, February, 66-74.

41. Chee, K. K.; Wong, M. K.; Lee, H. K. J. Chromatogr. 1996, 723, 259-271

42. Fish, J. R.; Revesz, R. LC-GC. 1996, 14, 3, 230-234.

43. Hoogerbrugge, R.; Molins, C.; Baumann, R. A. Anal. Chimi. Acta. 1997, 348, 247-253.

44. Lopez-Avila, V.; Young, R.; Teplitsky, N. J. AOAC Int. 1996, 79, 1, 142-156.

45. McMillin, R.; Miner, L. C.; Hurst, L. Spectrosc. 1997, 13, 4150.

46. Lopez-Avila, V.; Young, R.; Benedicto, J.; Ho, P.; Kim, R. Anal. Chem. 1995, 67, 2096-2102.

47. Lopez-Avila, V.; Benedicto, J.; Charan, C.; Young, R. Environ. Sci. Technol. 1995, 29, 2709-2712.
48. Lopez-Avila, V.; Young, R.; Kim, R. J. Chromatogr. Sci. 1995, 33, 481-484.

49. Frost, S. P.; Dean, J. R.; Evans, K. P.; Harradine, K.; Cary, C.; Comber, M. H. I. Analyst. 1997, 122, 895-898.

50. Llompart, M. P.; Lorenzo, R. A.; Cela, R.; Li, K.; B,langer, J. M. R.; Paré, J. R. J. J. Chromatogr. A 1997, 774, 243-251.

51. Lao, R. C.; Shu, Y. Y.; Holmes, J.; Chiu, C. Microchem. J. 1996, 53, 99-108.

52. Stout, S. J.; daCunha, A. R.; Allardice, D. G. Anal. Chem. 1996, 68, 653-658.

53. Molins, C.; Hogendoorn, E. A.; Heusinkveld, H. A. G.; van Harten, D. C.; van Zoonen, P.; Baumann, R. A. Chromatographia 1996, 43, 527-532.

54. Li, K.; B,langer, J. M. R.; Llompart, M. P.; Turpin, R. D.; Singhvi, R.; Paré, J. R. J. Spectroscopy. 1997, 13, 1-13.

55. Hwang, E.; Vanderveen, K. R., Microwave-extraction of polynuclear aromatic hydrocarbons from coal ash samples, poster $381 \mathrm{P}$ presented at the Pittsburg Conference in Analytical Chemistry and Applied Spectroscopy, New Orleans, Louisiana, USA, 5-10 March 1995.

56. Enders, B.; Schwedt, G. GIT Fachz. Lab. 1996, 3, 172-176.

57. Enders, B.; Schwedt, G. J. Prakt. Chem. 1997, 339, 250-255.

58. Budzinski, H.; Letellier, M.; Baumard, P.; Garrigues, P. Combined Protocol for the analysis of polyccylic aromatic hydrocarbons and polychlorobiphenyls from sediments using focussed microwave assisted extraction and purification, Poster 545P presented at the 48th Pittsburgh Conference in Analytical Chemistry and Applied Spectroscopy, Atlanta, March 16-21, 1997.

59. Garcia-Ayuso, L. E.; Sanchez M., Fernadez de Alba, A.; Luque de Castro, M. D. Anal. Chem. 1998, 70, 2426-2431.

60. Budzinski, H.; Letellier, M.; Garrigues, P.; LeMenach, K. J. Chromatogr., in press.

61. Letellier, M.; Budzinski, H.; Charrier, L.; Capes, S.; Dorthe, A. M. Fresenius' J. Anal. Chem. 1999, 364, 228-237.

62. Dupeyron, S.; Dudermel, P. M.; Couturier, D. Analusis 1997, 25, 286-292.

63. Letellier, M.; Budzinski, H.; Garrigues, P.; Wise, S. Spectroscopy 1997, 13, 71-80.

64. Budzinski, H.; Pirard, C.; Garrigues, P.; Math,, D. Microwave assisted extraction of polychlorobiphenyls from standard reference materials and sediments, presented at the 46th Pittsburgh Conference in Analytical Chemistry and Applied Spectroscopy, New Orleans, March 6-9, 1995.

65. Budzinski, H.; Letellier, M.; Baumard, P.; Garrigues, P. Focused Microwave assisted extraction of Polycyclic Aromatic Hydrocarbons (PAHs) and Polychlorobiphenyls (PCBs) from environmental samples (sediments, soils, biological tissues), presented at the 47th Pittsburgh Conference in Analytical Chemistry and Applied Spectroscopy, Chicago, March 3-8, 1996.

66. Letellier, M.; Budzinski, H.; Le Menach, K.; Garrigues, P. Focused Microwave assisted extraction of organic contaminants (PAHs, PCBs, Pesticides, alkanes) from environmental matrices, presented at 8th Annual Meeting of SETAC-Europe, Bordeaux, France, April 14-18, 1998.

67. Onuska, F. I.; Terry, K. A. J. Microcol. Separations 1995, 7(4), 319-326.

68. Onuska, F. I.; Terry, K. A. J. High Resol. Chromatogr. 1995, 18, 417-421. 


\section{Original articles}

69. Paré, J. R. J.; B,langer, J. M. R.; Thornon, D. E.; Li, K. Llompart, M. P.; Fingas, M.; Blenkinsopp, S. A. Spectroscopy 1997, 13, 23-32.

70. Steinheimer, T. R. J. Agric. Food Chem. , 41, 588-595.

71. Llompart, M. P.; Lorenzo, R. A.; Cela, R.; Paré, J. R. J.; B,langer, J. M. R.; Li, K. J. Chromatogr. A 1997, 757, 153164.
72. Paré, J. R. J.; Bélanger, J. M. R.; Li, K.; Stafford, S. S. J. Microcol. Sep. 1995, 7, 37-40.

73. Paré, J. R. J.; Bélanger, J. M. R.; Li, K.; Llompart, M. P.; Singhvi, R.; Turpin, R. D. Spectroscopy 1997, 13, 89-98. 